\title{
The Supervision of Dough Fermentation Using Image Analysis Complemented by a Continuous Discrete Extended Kalman Filter
}

\author{
Olivier Paquet-Durand *, Viktoria Zettel, Abdolrahim Yousefi-Darani and Bernd Hitzmann \\ Department of Process Analytics and Cereal Science, University of Hohenheim, Garbenstr. 23, \\ 70599 Stuttgart, Germany; Viktoria.Zettel@uni-hohenheim.de (V.Z.); rahim@uni-hohenheim.de (A.Y.-D.); \\ Bernd.Hitzmann@uni-hohenheim.de (B.H.) \\ * Correspondence: Olivier.Paquet-Durand@Uni-Hohenheim.de; Tel.: +49-711-459-22751
}

Received: 9 November 2020; Accepted: 16 December 2020; Published: 17 December 2020

\begin{abstract}
Dough fermentation is an important step during the preparation of fermented baking goods. For the supervision of dough fermentation, a continuous-discrete extended Kalman filter was applied, which uses an image analysis system as the measurement. By estimation a fixed number of gas bubbles inside the dough, the radius of an average bubble was determined. A mathematical dough model was used by the extended Kalman filter to estimate the radius of the average bubble, the $\mathrm{CO}_{2}$ concentration of the non-gas dough phase and the number of $\mathrm{CO}_{2}$ molecules in the average bubble. During a fermentation of $50 \mathrm{~min}$, the extended Kalman filter estimated that the average radius increased from $50 \mu \mathrm{m}$ to $127 \mu \mathrm{m}$, the $\mathrm{CO}_{2}$ concentration in the non-gas dough increased to $23 \mathrm{~mol} / \mathrm{m}^{3}$, and the $\mathrm{CO}_{2}$ amount in the bubble increased from $0.1 \times 10^{-10}$ to $4 \times 10^{-10} \mathrm{~mol}$. Also, the specific $\mathrm{CO}_{2}$ production rate was estimated to be in the range from $1.5 \times 10^{-3}$ to more than $4 \times 10^{-3} \mathrm{~mol} \cdot \mathrm{m}^{3} / \mathrm{kg} / \mathrm{s}$. The advantages of an extended Kalman filter for the supervision of the dough fermentation process are discussed.
\end{abstract}

Keywords: dough fermentation; extended Kalman filter; model; estimation

\section{Introduction}

In the preparation of baking goods, dough fermentation is one of the most important steps. Although fermentations of doughs have been applied for several thousand years, online measurement systems for important process variables are still rare [1]. During this process step, the basis for the later structure of the pore system of the final product is set. The bubbles introduced during the kneading will increase in volume, due to the diffusion of $\mathrm{CO}_{2}$, which is produced by the yeast cells. The dough fermentation process depends on the quality and amount of yeast cells added during mixing, the dough stability, the flour quality, the ingredients, and the dough yield as well as the fermentation conditions (temperature, humidity, air flow, and fermentation time) [2-4].

For the supervision of the dough fermentation process, several approaches have been developed. Cuenca et al. [5] applied isothermal micro-calorimetry to monitor food fermentation processes. Analyzing the maximum heat flow, the time to reach the maximum heat flow, and the enthalpy, they could demonstrate that the flour mixtures had a strong influence on all these values. Thus, a characterization of the process based on micro-calorimetry seems possible. Moreover, different optical systems were developed. Chevallier et al. [6] measured the expansion of bread dough during fermentation. Three methods for image acquisition with a digital camera were used: vertical expansion of the dough in a flask, horizontal expansion between two plates, and free expansion. The evaluation of the measurements based on the Gompertz function showed that the proving temperature had a 
significant effect on the different function parameters calculated (volume expansion ratio, expansion rate), while the water content had no significant effect. Zettel et al. [7] described a camera system that was able to determine the volume of dough pieces in a proofing chamber. Based on a mathematical model by Stanke et al. [8], it was possible to predict the volume change over time based on measurements obtained after 300,600 , and $3000 \mathrm{~s}$ of fermentation. The mean percentage difference of measured and overall simulated values (including fit and forecast) was $2.1 \%, 1.3 \%$, and $0.8 \%$ for the fit after 300, 600, and $3000 \mathrm{~s}$, respectively. Based on an image analysis system, Yousefi-Darani et al. [9] determined the relative volume increase of dough pieces in a proofing chamber and used this for a PID (proportional integral derivative) closed-loop control system. They demonstrated the controller performance by using different amounts of yeast as well as different starting temperatures of the dough pieces (normal state, frozen state, and thawed state). Comparing PID control with a fuzzy control system, Yousefi-Darani et al. [10] showed that similar results of both control algorithms were obtained, but that the fuzzy controller was much faster to implement. Ivorra et al. [11] developed a 3D vision system for the monitoring of dough fermentation; using a laser and a camera system combined using the structured light technique, they obtained a 3D sample profile during fermentation. Differences in dough behaviors during fermentation were found based on the structured light method. They related the variation of the total transversal area to the maximum height at each fermentation time and obtained a set of peaks and valleys. The number of peaks can be used to obtain information about the fermentation capacity of the samples. In a further study by that research team, Verdú et al. [12] obtained information about the internal structure of bread dough during the fermentation process using their 3D vision system as well as 2D images of baked dough samples. They observed correlations between the 3D and 2D information, specifically between the transversal area and height (3D) and final bubble size and number of bubbles (2D). A similar approach was presented by Giefer et al. [13], who applied a movable laser sensor system that was located at the back of the fermentation chamber and complemented it with a superellipsoid model fitting method. They showed that the volume of each object could be estimated with a deviation of approximately $10 \%$ on average.

To reduce the errors in measurements and to estimate non-measurable process variables, a Kalman filter can be applied. Although there are several applications of the Kalman filter for fermentation processes [14-20], its application is still rare in the food area. Recently, Pongsuttiyakorn et al. [21] used weight sensors, which are inherently contaminated by noise, and complemented them with a Kalman filter to correct the real-time measured weight under various temperatures to determine the moisture content during the food drying process. They showed the effectiveness of their approach using pineapples as the food material. Azimi et al. [22] applied a special version of an extended Kalman filter for the produce wash system of lettuce. To obtain the best possible estimation performance, they used a particle swarm optimization algorithm to optimize offline the covariance matrices of the process noise. This matrix was then used by the Kalman filter in real-time to estimate the chemical oxygen demand in the wash water, the free chlorine concentration, the E. coli concentration in the wash water, as well as the E. coli level on the lettuce. Applying a sensitivity analysis, the authors demonstrated that the estimator had good robustness. To decontaminate the surfaces of potatoes, Ulloa et al. [23] applied a Luenberger observer, which is similar to a Kalman filter. Based on temperature and weight loss data, the developed observer was able to estimate the internal food temperatures. This is important to prevent thermal food damages such as cracking. Abdel-Jabbar et al. [24] applied a linear state space dynamic model to describe drying in continuous fluidized bed dryers. They used a Kalman filter to provide state estimates for an optimal state feedback control system and obtained acceptable performance even when starting with incorrect initial states. For a fuzzy control system for the gari (i.e., one of the most popular foods produced from cassava) fermentation plant, Odetunji and Kehinde [25] applied an algorithm based on the Kalman filter for calculating the parameters of a linear algebraic equation that yields the least squares of errors. 
In the present study, a continuous-discrete extended Kalman filter was applied to monitor and estimate important variables of a dough fermentation process over time. As the measurement system, an image analysis system was used to determine the total dough volume and radius of an average bubble inside of the fermentation good. The discrete measurements were complemented with a nonlinear dynamic mathematical dough model, based on the Bernoulli equation, the $\mathrm{CO}_{2}$ production by yeast cells, and diffusion processes. Using the extended Kalman filter, estimates of the bubble radius, the amount of $\mathrm{CO}_{2}$ molecules in a bubble, the $\mathrm{CO}_{2}$ concentration in the non-gas dough, and the production rate of $\mathrm{CO}_{2}$ were estimated online.

\section{Materials and Methods}

A detailed description of the Kalman filter can be found in the literature [26].

\subsection{Dynamic Mathematical Model for Dough Fermentation}

The model used in this investigation was described in detail by Stanke at al. [8]. The following assumptions were made for the modelling: during kneading, only nitrogen is introduced into the dough (because we assumed just anaerobic consumption of the sugars), no $\mathrm{CO}_{2}$ and no new bubbles are formed during fermentation, a pure Newtonian behavior of the dough is assumed so the Bernoulli equation can be used complemented by the continuity equation. Moreover, we assumed that the bubbles are spherical and homogeneously distributed throughout the dough, all bubbles have the same radius, the yeast and therefore the $\mathrm{CO}_{2}$ production is homogeneously distributed over the dough, growth of yeast is not considered, only $\mathrm{CO}_{2}$ diffusion is considered, no coalescence and disproportionation are considered, all the gas is retained in the dough, and the ideal gas law can be applied.

Therefore, for the extended Kalman filter, the following equations are obtained:

$$
\frac{d}{d t}\left[\begin{array}{c}
r \\
n \\
C_{D} \\
q_{\mathrm{CO}_{2}}
\end{array}\right]=\left[\begin{array}{c}
\frac{3 n R_{G} T}{16 \pi \mu r^{2}}-\frac{p_{D} r}{4 \mu}-\frac{\gamma}{2 \mu} \\
4 D \pi r\left(C_{D}-\frac{p_{D}}{H}\left(1-\left[\frac{r_{0}}{r}\right]^{3}\right)-\frac{8 \gamma}{H r}\left(1-\left[\frac{r_{0}}{r}\right]^{2}\right)\right) \\
q_{\mathrm{CO}_{2}} \mathrm{X}-4 \mathrm{~N}_{B} D \pi r\left(C_{D}-\frac{p_{D}}{H}\left(1-\left[\frac{r_{0}}{r}\right]^{3}\right)-\frac{8 \gamma}{H r}\left(1-\left[\frac{r_{0}}{r}\right]^{2}\right)\right) \\
0
\end{array}\right]+\left[\begin{array}{c}
z_{r}(t) \\
z_{n}(t) \\
z_{C_{D}}(t) \\
z_{q_{\mathrm{CO} 2}}(t)
\end{array}\right]
$$

where $r$ is radius of all bubbles, $\mathrm{t}$ is the time, $n$ is the amount of $\mathrm{CO}_{2}$ in mol in a single bubble, $C_{D}$ if the $\mathrm{CO}_{2}$ concentration in non-gaseous dough, $q_{\mathrm{CO}_{2}}$ is the specific $\mathrm{CO}_{2}$ production rate, $R_{G}$ is the gas constant, $T$ is the temperature, $\mu$ is the viscosity, $p_{D}$ is the pressure in the dough, $\gamma$. is the surface tension, $X$. is the yeast concentration, $D$ is the diffusion coefficient of $\mathrm{CO}_{2}, \mathrm{H}$ is the Henry constant for $\mathrm{CO}_{2}$ and water, $r_{0}$ is the radius at $t=0 \mathrm{~s}$, and $z_{i}(t)$ represents the non-correlated process error noise, whose expectation value is zero.

The last differential equation was introduced to estimate the specific $\mathrm{CO}_{2}$ production rate by the extended Kalman filter. Obviously, during the simulation no change will occur; however, during filtering, the values of the $\mathrm{CO}_{2}$ production will be adapted to the actual value.

\subsection{Image Acquisition System}

The dough pieces were placed in front of a camera (DFK 31BU03.H, Image Source Europe GmbH, Germany) with a resolution of $1024 \times 768$ pixel. They were positioned on a black baking pad to avoid reflections from light and to improve the border detection for the automated object acquisition. A picture was taken every three seconds and evaluated via a border detection script using MATLAB 2019a (version 9.6.0). The imaging evaluation software provides the radius of an average bubble assuming a fixed number of bubbles as $\mathrm{N}_{\mathrm{B}}$ and a start radius of the bubbles as $r(t=0)$. Their values are 
presented below. Therefore, as the only measurement for the extended Kalman filter, the radius of an average bubble was used in the following equation:

$$
y\left(t_{i}\right)=r\left(t_{i}\right)+w\left(t_{i}\right)
$$

Every $3 \mathrm{~s}$, a measurement was sent to the extended Kalman filter. To verify the volume measurement obtained by the image analysis system, the results were compared with those determined by a volume laser scanning system (Volscan profiler 600, Stable Micro Systems, Winopal Forschungsbedarf GmbH, Elze, Germany).

\subsection{Software Implementation}

The image analysis software as well as the extended Kalman filter were developed using the software Matlab ${ }^{\circledR}$ 2019a (version 9.6.0) and the "Symbolic Math" toolbox (version 8.3). The latter was used to calculate the estimation error covariance differential equation matrix (16 equations). For all calculations, a normal office PC (Intel Core ${ }^{\circledR}$ i5 8500 with 8 GiB of RAM) with Windows 10 was used. For the simulation, a system of $20(4+16)$ differential equations in total was solved numerically using the ode45 method from Matlab ${ }^{\circledR}$, which is based on an explicit Runge-Kutta formula.

\subsection{Preparation of Dough}

The doughs were prepared with commercial wheat flour (200 g, Schapfenmühle, type 550: $0.51-0.63 \%$ mineral supplements in dry matter, corrected to the moisture content), water $(119.18 \mathrm{~g})$, salt (4 g), and commercial yeast ( $2 \mathrm{~g}$, Omas Ur Hefe, Fala, Germany) in a mixer (N50, Hobart GmbH, Germany). Mixing time and water temperature were kept constant at $4 \mathrm{~min}$ and $32{ }^{\circ} \mathrm{C}$, respectively, and the temperature of the prepared dough ranged between 23.8 and $27.8^{\circ} \mathrm{C}$ depending on the room temperature. After the preparation, hand-rounded $50 \mathrm{~g}$ dough balls were set in a proving cabinet (Klimaschrank VC 4033, Vötsch Industrietechnik $\mathrm{GmbH}$, Germany) for 40 min at $30{ }^{\circ} \mathrm{C}$ and $80 \%$ humidity.

\subsection{Parameters of the Models and the Extended Kalman Filter}

The parameters used in the mathematical dough model and the extended Kalman filter are presented in Table 1. The amount of nitrogen in a bubble was calculated using the ideal gas law and the start radius of the representative bubble. Most of the values were taken from the literature. The diagonal values of the process noise spectral matrix $Q_{i i}$ were determined during simulations. A measurement error was assumed that was more than half of the radius $r(t=0)$; therefore, the measurement noise variance $\mathrm{R}$ was fixed at $10^{-9} \mathrm{~m}^{2}$. The initial conditions for the numerical solving of the differential equations for the mathematical dough model and the estimation error covariances are presented in Table 2. The values of $Q$ were obtained by performing experiments.

Table 1. Parameters used in the mathematical dough model and the extended Kalman filter.

\begin{tabular}{cccc}
\hline Parameter & Name & Value & Source \\
\hline $\mathrm{R}_{\mathrm{G}}$ & Gas constant & $8.314 \mathrm{~J} / \mathrm{mol} \mathrm{K}$ & {$[27]$} \\
$\gamma$ & Surface tension & $0.042 \mathrm{~J} / \mathrm{m}^{2}$ & {$[28]$} \\
$\mathrm{p}_{\mathrm{D}}$ & Pressure in dough & $101,325 \mathrm{~Pa}$ & Self-determined \\
$\mathrm{N}_{\mathrm{B}}$ & Number of bubbles & $2 \cdot 10^{11} / \mathrm{m}^{3}$ & Self-determined \\
$\mu$ & Viscosity & $4 \cdot 10^{7} \mathrm{~Pa} \cdot \mathrm{s}$ & {$[8]$} \\
$\mathrm{T}$ & Temperature & $303 \mathrm{~K}$ & Self-determined \\
$\mathrm{H}$ & Henry constant & $2.71 \cdot 10^{3} \mathrm{~J} / \mathrm{mol}^{2}$ & {$[29]$} \\
$\mathrm{D}$ & Diffusion coefficient & $7.2 \cdot 10^{-4} \mathrm{~m}^{2} / \mathrm{s}$ & {$[29]$} \\
$\mathrm{X}$ & Yeast concentration & $32 \mathrm{~kg} / \mathrm{m}^{3}$ & Self-determined \\
$\mathrm{Q}_{11}$ & Q-value r & $10^{-12} \mathrm{~m}^{2} / \mathrm{s}$ & Self-determined \\
$\mathrm{Q}_{22}$ & Q-value CO ${ }_{2}$ amount & $10^{-22} \mathrm{~mol}^{2} / \mathrm{s}$ & Self-determined \\
$\mathrm{Q}_{33}$ & Q-value C & $10^{-2} \mathrm{~mol}^{2} / \mathrm{m}^{6} \mathrm{~s}$ & Self-determined \\
$\mathrm{Q}_{44}$ & Q-Value CO $\mathrm{CO}_{2}$ production rate & $10^{-6} \mathrm{~mol}^{2} / \mathrm{m}^{6} \mathrm{~s}$ & Self-determined \\
$\mathrm{R}$ & Measurement noise variance & $10^{-9} \mathrm{~m}^{2}$ & Self-determined \\
\hline
\end{tabular}


Table 2. Initial conditions of the process variables and estimation error differential equations.

\begin{tabular}{cc}
\hline Process Variables & Value \\
\hline$r(t=0)$ & $5 \cdot 10^{-5} \mathrm{~m}$ \\
$n(t=0)$ & $0 \mathrm{~mol}$ \\
$C_{D}(t=0)$ & $0 \mathrm{~mol} / \mathrm{m}^{3}$ \\
$q_{\mathrm{CO}_{2}}(t=0)$ & $1.5 \cdot 10^{-3} \mathrm{~mol} / \mathrm{kg} / \mathrm{s}$ \\
$P_{r r}(t=0)$ & $1 \cdot 10^{-10} \mathrm{~m}^{2}$ \\
$P_{n n}(t=0)$ & $3 \cdot 10^{-20} \mathrm{~mol}^{2}$ \\
$P_{C_{D} C_{D}}(t=0)$ & $250 \mathrm{~mol}^{2} / \mathrm{m}^{6}$ \\
$P_{p \mathrm{CO}_{2} p \mathrm{CO}_{2}}(t=0)$ & $7.5 \cdot 10^{-4} \mathrm{~mol}^{2} \cdot \mathrm{m}^{6} / \mathrm{kg}^{2} / \mathrm{s}^{2}$ \\
\hline
\end{tabular}

\section{Results}

Figure 1 presents the online measurements of the bubble radius (see Table S1, Supplementary Material), its estimated values, as well as the purely simulated values using just the initial conditions. When a deviation of the measured and estimated values was present, the estimated values tended towards the measured ones, indicating that the mathematical dough model was not dominating the estimation. At around $645 \mathrm{~s}$ fermentation time, the imaging system presented the same radius several times, and as a consequence, the estimated radius were increasing more slowly. Overall, there were 423 measurements below and 418 measurements above the estimated values, indicating that there was no systematic deviation due to the estimation. During the fermentation, the radius more than doubled its value, which shows that the gas volume increased by more than eight fold. Considering a start volume of $10 \%$ of the total dough volume, then the final dough volume was 2.4 times its start value. The purely simulated values were in between 500 and $1500 \mathrm{~s}$ below the estimated and after $1700 \mathrm{~s}$ above them. This indicated that the cells produced more $\mathrm{CO}_{2}$ during the first time period and less at the end. A difference of $7 \mu \mathrm{m}$ between the simulated and estimated radius was present at the end of fermentation. The overall simulated and estimated values followed roughly the same line, indicating that the values of $\mathrm{R}$ and $\mathrm{Q}$ might be balanced. If only the values of the radius are considered, the advantage of the extended Kalman filter is not immediately obvious.

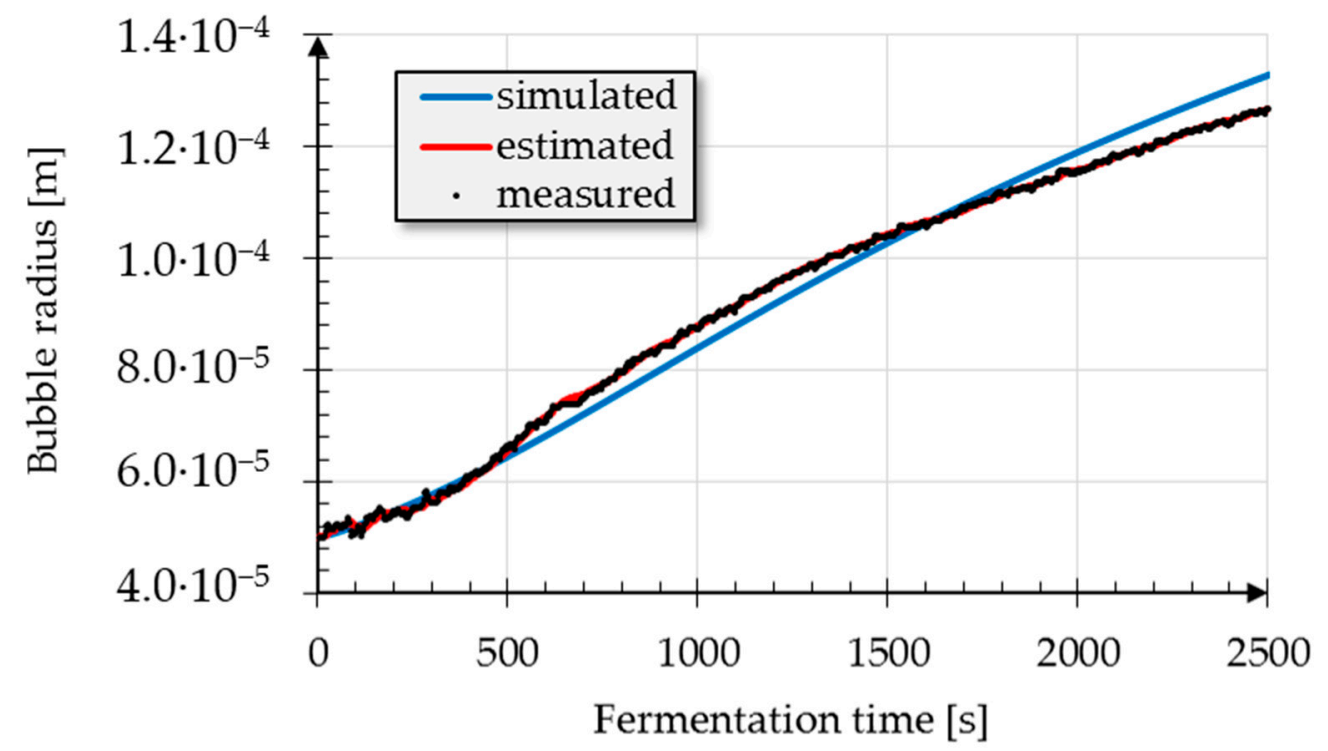

Figure 1. Bubble radii calculated by the imaging system compared to the values estimated by the extended Kalman filter as well as simulated values. 
However, further information was obtained, as shown in Figure 2, where the $\mathrm{CO}_{2}$ amount in the representative bubble is presented as estimated and simulated. Here, a similar behavior can be recognized. However, the estimated values were higher here from slightly before $500 \mathrm{~s}$ to $1400 \mathrm{~s}$ and always lower after $1500 \mathrm{~s}$. At $645 \mathrm{~s}$, the increase of the $\mathrm{CO}_{2}$ values reduces significantly. This is the consequence of the constant values of the radius measurements. At the end of the fermentation, a difference of almost $10^{-10} \mathrm{~mol}$ can be seen, indicating that the cells might have had less amount of substrate available, which can be due to less damaged starch due to lower enzyme activity converting amylose and amylopectin to fermentable sugars. The different evolution of the simulated and estimated values was more pronounced around $100 \mathrm{~s}$, as seen in Figure 3.

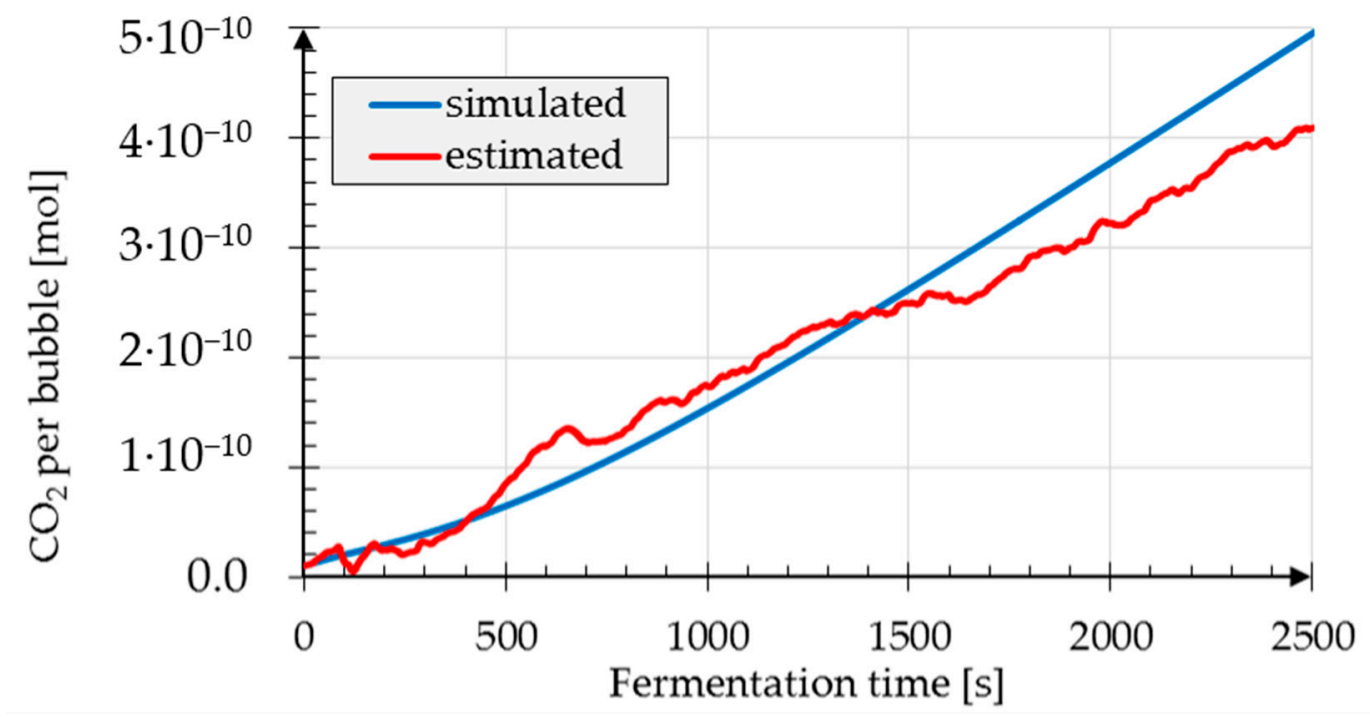

Figure 2. Simulated and Kalman estimation of the amount of $\mathrm{CO}_{2}$ in a bubble.

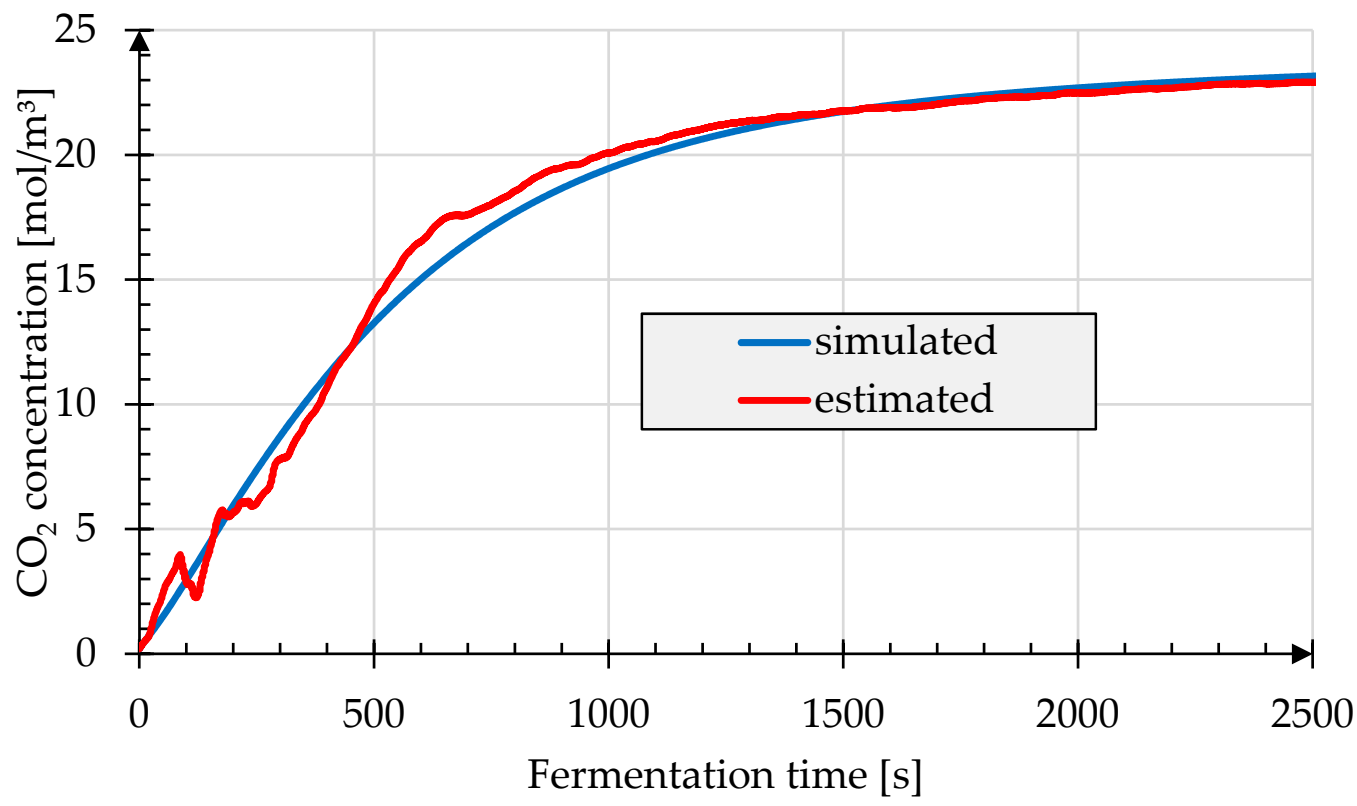

Figure 3. Simulated and Kalman estimation of the $\mathrm{CO}_{2}$ concentration in non-gaseous dough.

In Figure 3, the simulated and estimated values of the $\mathrm{CO}_{2}$ concentration in the non-gaseous dough phase are presented. After a steep linear increase at the beginning of fermentation, a saturation seems to be reached at the end. Roughly before $100 \mathrm{~s}$, the estimated values decrease significantly, which is due to the fact that the measurements of the radius decrease, which seems to be an error of 
the image evaluation system. The measurements of the radius are smaller than the estimated radius. To compensate that, the $\mathrm{CO}_{2}$ in the non-gas phase as well as the amount of $\mathrm{CO}_{2}$ in the representative bubble were almost constant until the radius increased again. However, after that fermentation time, the values of the $\mathrm{CO}_{2}$ in the non-gaseous dough phase converged slowly to the saturation value. However, the amount of $\mathrm{CO}_{2}$ in a bubble still increased almost linearly.

The values of the specific $\mathrm{CO}_{2}$ production rate fluctuated even more, as one can see in Figure 4. At the beginning, an up and down trend can be observed, which is due to the increased and decreased radius measurements around $100 \mathrm{~s}$ fermentation time. After $250 \mathrm{~s}$, a steep increase in the $\mathrm{CO}_{2}$ production rate to almost the double value can be seen. After $645 \mathrm{~s}$ fermentation time, the production rate decreased to levels under the start value, the lowest value being reached at $1650 \mathrm{~s}$ fermentation time. The increase at the beginning might be due to the increase in temperature, which was higher in the fermentation chamber than during the dough preparation. The decrease might be a result of the limiting substrate concentration, as only damaged starch can be converted to fermentable sugars. The fermentation lasted more than $40 \mathrm{~min}$, so most probably the cell number increased due to growth. However, this was not considered in the model ( $\mathrm{X}$ is constant). If the cell count increased in reality but not in the model, then the filter could compensate for this fact by an increase in the specific $\mathrm{CO}_{2}$ production rate, which might explain the moderate increase during the last $800 \mathrm{~s}$.

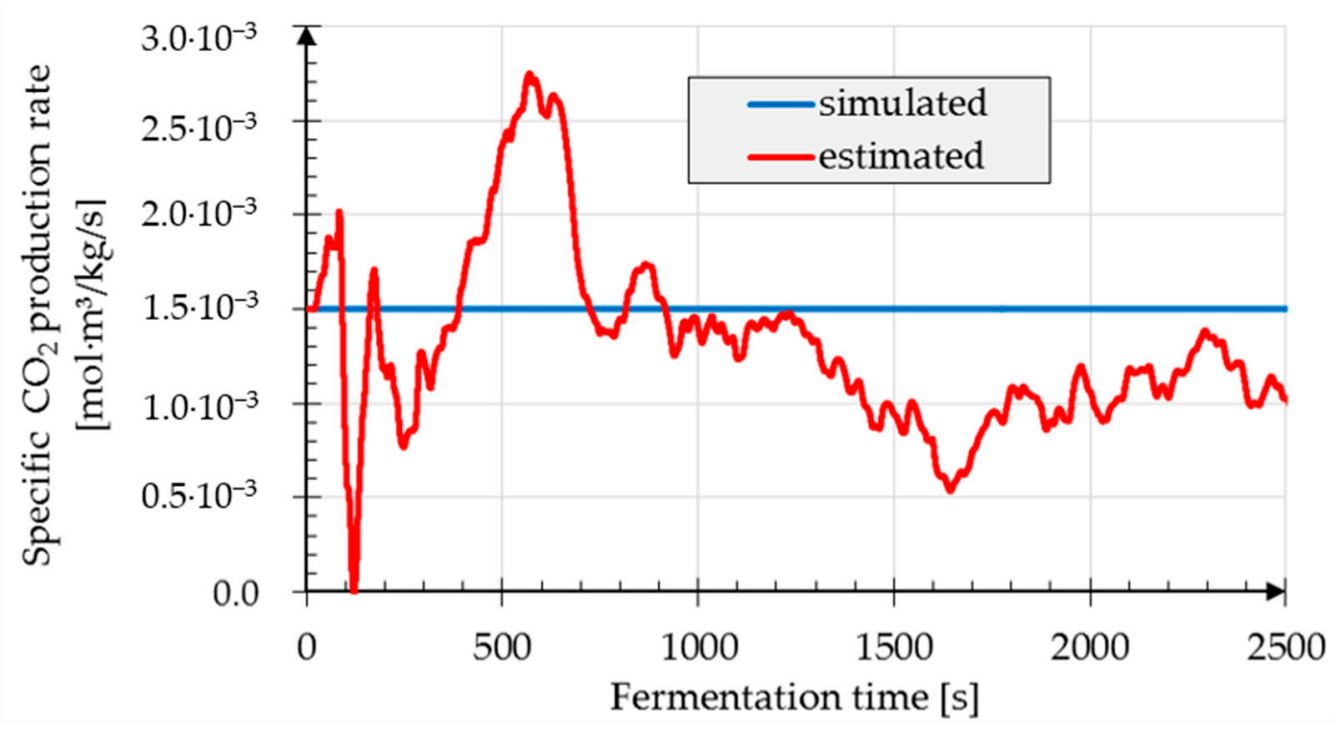

Figure 4. Simulated and Kalman estimation of the specific $\mathrm{CO}_{2}$ production rate.

Further information obtained by the extended Kalman filter algorithm can be seen in Figures 5 and 6, where the square root of the estimation error variances of the radius, the specific $\mathrm{CO}_{2}$ production rate, the $\mathrm{CO}_{2}$ in non-gas dough, and the $\mathrm{CO}_{2}$ amount in the bubble can be seen. For the radius, after a short decrease, the values jumped up to $1.15 \times 10^{-5} \mathrm{~m}$, due to the difference between the measured and estimated values for the radius, and then decreased slowly to $8.5 \times 10^{-6} \mathrm{~m}$ with a fast up and down trend every $3 \mathrm{~s}$. The values increased when no measurement was present and decreased rapidly during the filtering, when a measurement was obtained; therefore, the line appears thick. This was also true for the other estimated variables but with a much smaller amplitude. The estimation error of the specific $\mathrm{CO}_{2}$ production rate presented a steep decrease to $0.014 \mathrm{~mol} \cdot \mathrm{m}^{3} / \mathrm{kg} / \mathrm{s}$ during the first $300 \mathrm{~s}$ fermentation time, followed by a gentle increase to $0.016 \mathrm{~mol} \cdot \mathrm{m}^{3} / \mathrm{kg} / \mathrm{s}$ at the end of fermentation. 


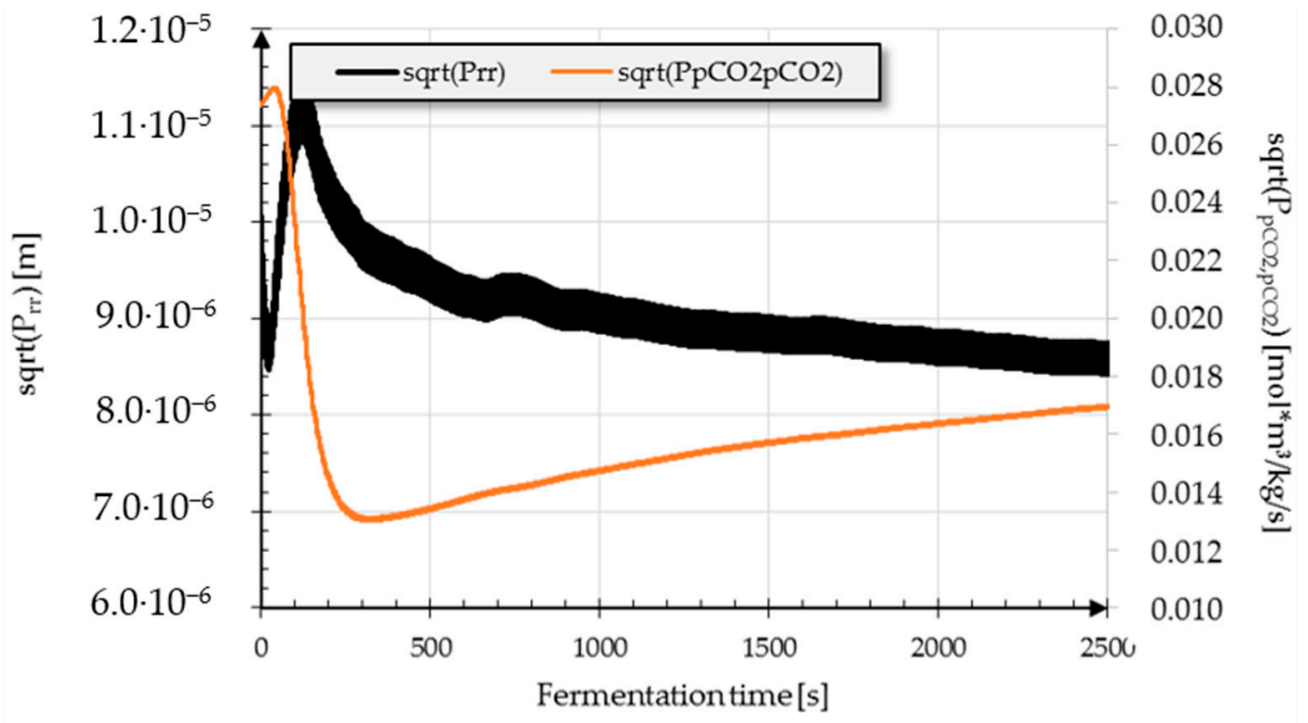

Figure 5. Estimation error variance of the radius and the specific $\mathrm{CO}_{2}$ production rate.

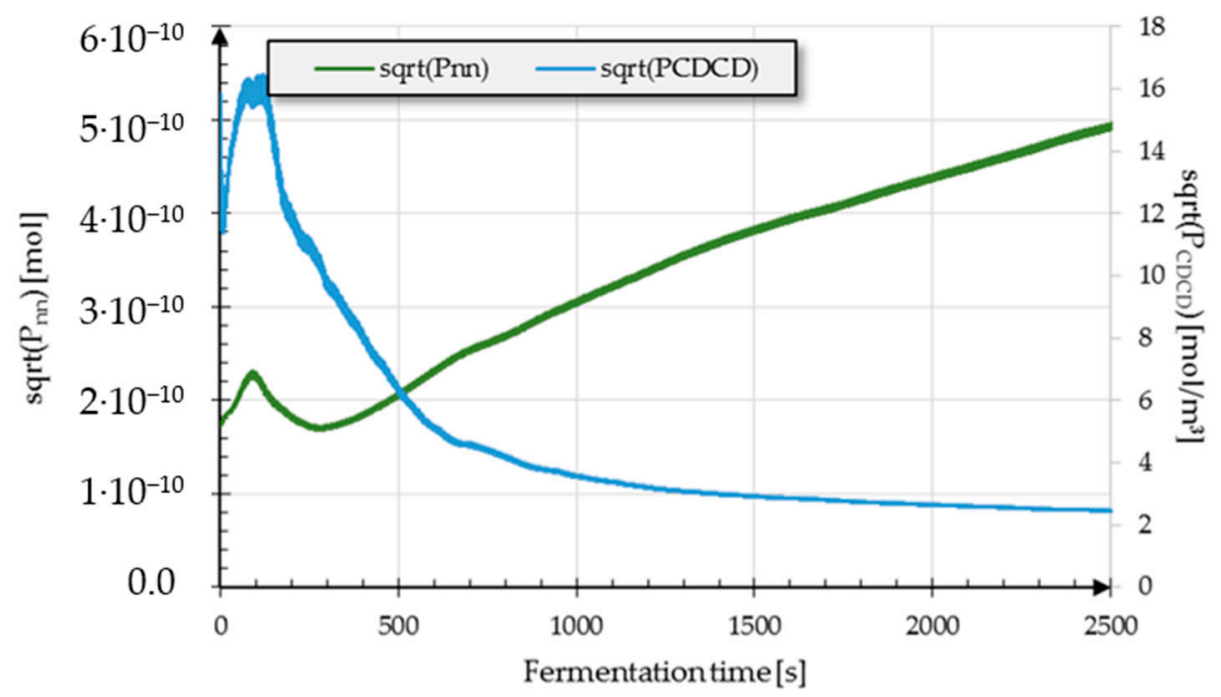

Figure 6. Estimation error of the $\mathrm{CO}_{2}$ in non-gaseous dough and the amount of $\mathrm{CO}_{2}$ in the bubble.

The estimation error of the amount of $\mathrm{CO}_{2}$ in the representative bubble, with an exception at the beginning, increased almost linearly. The values for $\mathrm{CO}_{2}$ in the non-gas phase jumped at the beginning to $16 \mathrm{~mol} / \mathrm{m}^{3}$ and after a while decreased almost exponentially to roughly $2 \mathrm{~mol} / \mathrm{m}^{3}$. The reason for the decrease might be that the values approach the saturation level.

If the square roots of the median values of the estimation error variances are divided by the median of the corresponding process variables, the following values are obtained: 0.09 for the radius, 0.15 for the $\mathrm{CO}_{2}$ in the non-gaseous dough, 1.5 for the amount of $\mathrm{CO}_{2}$ in the bubble, and 13 for the specific $\mathrm{CO}_{2}$ production rate. Therefore, the specific $\mathrm{CO}_{2}$ production rate had the highest relative estimation error, and the error was much higher than the values themselves. The values of the amount of $\mathrm{CO}_{2}$ in the bubble had an error of same order of magnitude as the corresponding $\mathrm{CO}_{2}$ values. The estimation errors of the radius and the $\mathrm{CO}_{2}$ in the non-gaseous dough phase were one order of magnitude smaller than the values of the corresponding process variables.

To prove the capability of the extended Kalman filter for the estimation of the specific $\mathrm{CO}_{2}$ production rate, two new runs of the extended Kalman filter were carried out changing the biomass concentration $X$. The yeast cell mass in the model was changed to analyze the estimation performance of the extended Kalman filter. Figure 7 shows the specific $\mathrm{CO}_{2}$ production rate in three different runs 
of the extended Kalman filter using the same measurements: one run where the biomass concentration was correctly specified $\left(X=32 \mathrm{~kg} / \mathrm{m}^{3}\right)$, one with half of the value $\left(X=16 \mathrm{~kg} / \mathrm{m}^{3}\right)$, and one with twice as much $\left(X=64 \mathrm{~kg} / \mathrm{m}^{3}\right)$. To compare the values more easily, the production rate was divided or multiplied by 2 where half or twice as much yeast concentration was assumed, respectively. For the production rate of half the yeast concentration, it took more than $800 \mathrm{~s}$ for the filter until the correct value was obtained. This was much faster when twice the yeast concentration was assumed. Here, after $250 \mathrm{~s}$ the correct value was reached. The pattern of the correct values and the one obtained with twice the yeast concentration were almost the same, although sometimes the values were smaller, sometimes higher; but the same up and down trend was clearly followed. This indicates that the values themselves might be better than the estimation error variance suggests.

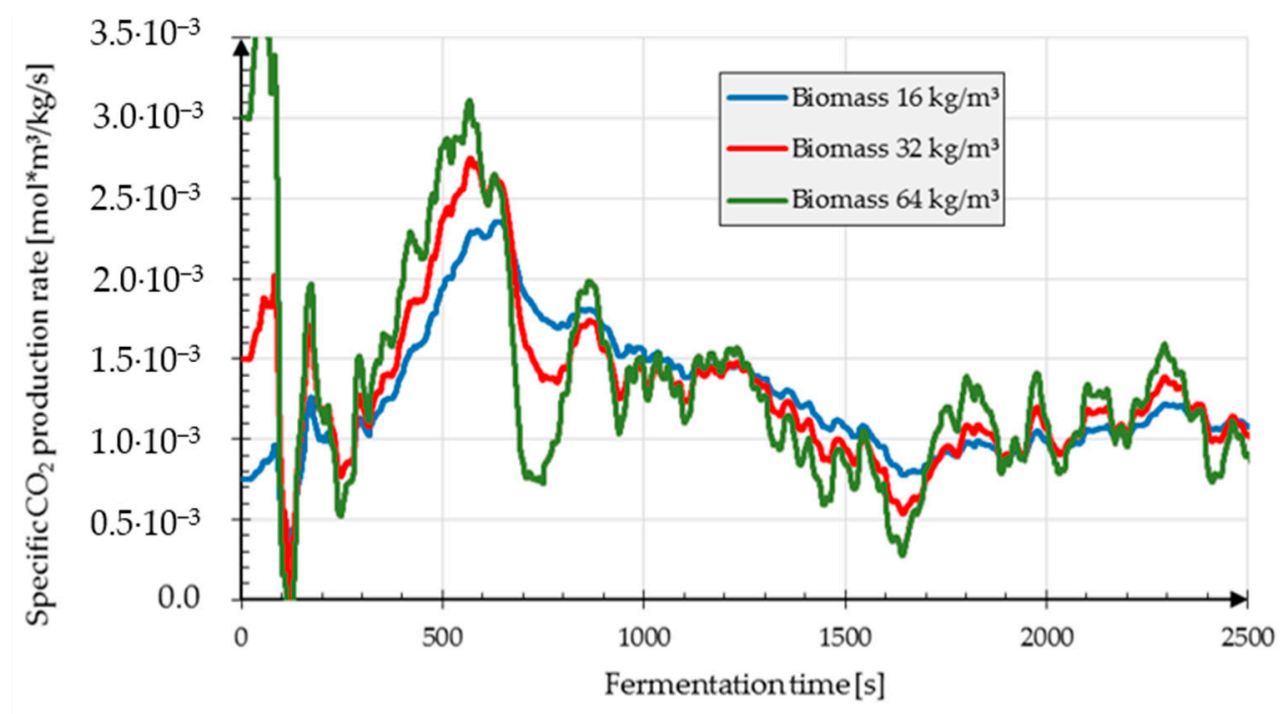

Figure 7. Estimated specific $\mathrm{CO}_{2}$ production rate calculated during three runs of the extended Kalman filter with the same measurements but with different assumed yeast concentrations; the production rate was multiplied by 2 where the yeast concentration was considered to be $64 \mathrm{~kg} / \mathrm{m}^{3}$; the production rate was divided by 2 where the yeast concentration was considered to be $16 \mathrm{~kg} / \mathrm{m}^{3}$; the correct yeast concentration was $16 \mathrm{~kg} / \mathrm{m}^{3}$.

Although some of the estimation errors were high, the information obtained with the extended Kalman filter for the supervision of dough fermentation was significant. More information was obtained beyond the volume of dough pieces.

\section{Conclusions}

Dough fermentation is an important step during the preparation of fermented baking goods. Therefore, its supervision is mandatory. Here, an image analysis system was presented that is able to determine the volume of the fermented dough pieces. Combining this information with the number of bubbles inside a dough, an average radius can be determined online. This measurement information was complemented with a mathematical dough model for the estimation of the bubble radius, the $\mathrm{CO}_{2}$ in non-gas dough, the $\mathrm{CO}_{2}$ in an average although representative bubble, and the specific $\mathrm{CO}_{2}$ production rate. Therefore, detailed information can be gathered online using an extended Kalman filter for further evaluation beyond "just" volume information. During the first minutes of the fermentation time, the specific $\mathrm{CO}_{2}$ production rate is determined and can then be used to assess the current process state and evaluate its further evolution. The computing time for the extended Kalman filter is negligible; thus, even embedded computers can be used for this application. 
Supplementary Materials: The following are available online at http://www.mdpi.com/2227-9717/8/12/1669/s1, Table S1: Measurements used for the extended Kalman filter.

Author Contributions: Conceptualization, O.P.-D. and V.Z.; methodology, A.Y.-D.; validation, A.Y.-D.; writing-review and editing, O.P.-D., V.Z., A.Y.-D. and B.H.; supervision, B.H.; funding acquisition, B.H. All authors have read and agreed to the published version of the manuscript.

Funding: This IGF Project of the FEI was supported via AiF within the programme for promoting the Industrial Collective Research (IGF) of the German Ministry of Economic Affairs and Energy (BMWi), based on a resolution of the German Parliament.

Conflicts of Interest: The authors declare no conflict of interest.

\section{References}

1. Hitzmann, B. Special Issue: Bioprocess Monitoring and Control. Processes 2020, 8, 854. [CrossRef]

2. Campbell, G.; Chiotellis, E.; Campbell, G.M. Proving of bread dough II: Measurement of gas production and retention. Food Bioprod. Process: Trans. Inst. Chem. Eng. Part C 2003, 81, 207-216.

3. Cauvain, S.P. Bread Making, Improving Quality, 2nd ed.; Woodhead Puiblishing: Cambridge, UK, 2012.

4. Birch, A.N.; Berg, F.W.J.V.D.; Hansen, Å.S. Expansion profiles of wheat doughs fermented by seven commercial baker's yeasts. J. Cereal Sci. 2013, 58, 318-323. [CrossRef]

5. Cuenca, M.; Romen, B.; Gatti, G.; Mason, M.; Scampicchio, M. Microcalorimetry as a tool for monitoring food fermentations. Chem. Eng. Trans. 2017, 57, 1957-1962.

6. Chevallier, S.; Zuniga, R.; Le-Bail, A. Assessment of bread dough expansion during fermentation. Food Bioprocess Technol. 2010, 5, 609-617. [CrossRef]

7. Zettel, V.; Paquet-Durand, O.; Hecker, F.; Hitzmann, B. Image analysis and mathematical modelling for the supervision of the dough fermentation process. AIP Conf. Proc. 2016, 1769, 180003. [CrossRef]

8. Stanke, M.; Zettel, V.; Schütze, S.; Hitzmann, B. Measurement and mathematical modeling of the relative volume of wheat dough during proofing. J. Food Eng. 2014, 131, 58-64. [CrossRef]

9. Yousefi-Darani, A.; Paquet-Durand, O.; Zettel, V.; Hitzmann, B. Closed loop control system for dough fermentation based on image processing. J. Food Process. Eng. 2018, 41, e12801. [CrossRef]

10. Yousefi-Darani, A.; Paquet-Durand, O.; Hitzmann, B. Application of fuzzy logic control for the dough proofing process. Food Bioprod. Process. 2019, 115, 36-46. [CrossRef]

11. Ivorra, E.; Amat, S.V.; Sanchez, A.J.; Barat, J.M.; Grau, R. Continuous monitoring of bread dough fermentation using a 3D vision Structured Light technique. J. Food Eng. 2014, 130, 8-13. [CrossRef]

12. Verdú, S.; Ivorra, E.; Sanchez, A.J.; Barat, J.M.; Grau, R. Relationship between fermentation behavior, measured with a 3D vision Structured Light technique, and the internal structure of bread. J. Food Eng. 2015, 146, 227-233. [CrossRef]

13. Giefer, L.; Lütjen, M.; Rohde, A.-K.; Freitag, M. Determination of the optimal state of dough fermentation in bread production by using optical sensors and deep learning. Appl. Sci. 2019, 9, 4266. [CrossRef]

14. Hitzmann, B.; Broxtermann, O.; Cha, Y.-L.; Sobieh, O.; Stärk, E.; Scheper, T. The control of glucose concentration during yeast fed-batch cultivation using a fast measurement complemented by an extended Kalman filter. Bioprocess Biosyst. Eng. 2000, 23, 337-341. [CrossRef]

15. Arndt, M.; Kleist, S.; Miksch, G.; Friehs, K.; Flaschel, E.; Trierweiler, J.; Hitzmann, B. A feedforward-feedback substrate controller based on a Kalman filter for a fed-batch cultivation of Escherichia coli producing phytase. Comput. Chem. Eng. 2005, 29, 1113-1120. [CrossRef]

16. Klockow, C.; Hüll, D.; Hitzmann, B. Model based substrate set point control of yeast cultivation processes based on FIA measurements. Anal. Chim. Acta 2008, 623, 30-37. [CrossRef] [PubMed]

17. Yousefi-Darani, A.; Paquet-Durand, O.; Hitzmann, B. The Kalman filter for the supervision of cultivation processes. Adv. Biochem. Eng. Biotechnol. 2020, in press.

18. Abadli, M.; Dewasme, L.; Tebbani, S.; Dumur, D.; Wouwer, A.V. Generic model control applied to E. coli BL21(DE3) fed-batch cultures. Processes 2020, 8, 772. [CrossRef]

19. Krämer, D.; Wilms, T.; King, R. Model-based process optimization for the production of macrolactin D by Paenibacillus polymyxa. Processes 2020, 8, 752. [CrossRef]

20. Lisci, S.; Grosso, M.; Tronci, S. A Geometric observer-assisted approach to tailor state estimation in a bioreactor for ethanol production. Processes 2020, 8, 480. [CrossRef] 
21. Pongsuttiyakorn, T.; Sooraksa, P.; Pornchalermpong, P. Simple Effective and robust weight sensor for measuring moisture content in food drying process. Sens. Mater. 2019, 31, 2393. [CrossRef]

22. Azimi, V.; Munther, D.; Fakoorian, S.A.; Nguyen, T.T.; Simon, D. Hybrid extended Kalman filtering and noise statistics optimization for produce wash state estimation. J. Food Eng. 2017, 212, 136-145. [CrossRef]

23. Ulloa, R.Z.; Rouaud, O.; Havet, M.; Boillereaux, L. Observer-based tracking control of superficial temperature. J. Food Eng. 2006, 76, 70-78. [CrossRef]

24. Abdel-Jabbar, N.M.; Jumah, R.Y.; Ali, M.A.-H. State estimation and state feedback control for continuous fluidized bed dryers. J. Food Eng. 2005, 70, 197-203. [CrossRef]

25. Odetunji, O.A.; Kehinde, O.O. Computer simulation of fuzzy control system for gari fermentation plant. J. Food Eng. 2005, 68, 197-207. [CrossRef]

26. Gelb, A. Applied Optimal Estimation; MIT Press: Cambridge, MA, USA, 1999.

27. Perry, R.H.; Green, D.W.; Maloney, J.O. Perry's Chemical Engineers' Handbook, 7th ed.; McGraw-Hill: New York, NY, USA, 1997.

28. Grenier, D.; Lucas, T.; Le Ray, D. Measurement of local pressure during proving of bread dough sticks: Contribution of surface tension and dough viscosity to gas pressure in bubbles. J. Cereal Sci. 2010, 52, 373-377. [CrossRef]

29. Chiotellis, E.; Campbell, G.M. Proving of bread dough I: Modelling the evolution of the bubble size distribution. Food Bioprod. Process. 2003, 81, 194-206. [CrossRef]

Publisher's Note: MDPI stays neutral with regard to jurisdictional claims in published maps and institutional affiliations.

(C) 2020 by the authors. Licensee MDPI, Basel, Switzerland. This article is an open access article distributed under the terms and conditions of the Creative Commons Attribution (CC BY) license (http://creativecommons.org/licenses/by/4.0/). 